\title{
Regionalism, Trade and Growth: The Case of the EU-South Africa Free Trade Arrangement
}

\author{
Soamiely Andriamananjara* and Russell Hillberry \\ U.S. International Trade Commission ${ }^{* *}$
}

\begin{abstract}
In a sequential Computable General Equilibrium analysis, we investigate the likely effects of the EU-South Africa Free Trade Area (FTA), with a special emphasis on South Africa's growth prospects. We find that the FTA would increase South African welfare as well as output. We note, however, that the gains are very modest when viewed in the context of the time period over which full adjustment to the treaty provisions is expected to occur. Only 2 percent of the economic growth expected over the next 18 years in South Africa can be linked to additional trade associated with the FTA. The long phase-in period and the partial benefits of regionalism limit the importance of trade as an engine of growth.
\end{abstract}

JEL Classification Numbers: F15, F17, F43

Keywords: Free Trade Area, South Africa, European Union

\section{Introduction}

\footnotetext{
* Corresponding author: Office of Economics, U.S. International Trade Commission, 500 E Street SW, Washington, D.C. 20436, USA, phone: 1-202-205-3252, fax: 1-202-205-2340, email: soamiely@usitc.gov.

${ }^{* *}$ The findings, interpretations and conclusions expressed in this paper are entirely those of the authors and do not necessarily represent the view of the US International Trade Commission or any of its individual Commissioners.
} 
On October 11, 1999, the European Union (EU) and the Republic of South Africa ratified the "Agreement on Trade, Development and Cooperation between the European Community and its Member States and the Republic of South Africa " (TDCA). Gaining preferential treatment in one of the world's largest markets is undoubtedly a major diplomatic coup for South Africa, but is it likely to have the beneficial economic effects that have been advertised? We estimate the effects of the Agreement, as signed by the parties, in a sequential simulation of the static Global Trade Analysis Project (GTAP) model. Within this framework, we incorporate outside estimates of South Africa's dynamic gains from trade, and compare the results to a plausible growth path for South Africa. The inclusion of dynamic benefits increases South Africa's gains from the TDCA.

However, the gains from additional EU-South Africa trade appear quite small when measured against plausible forecasts of South African growth. Using an 18-year time path to allow for full implementation and adjustment to the Agreement, we estimate that, even with the assumption of dynamic gains from trade, the TDCA should only be expected to account for 2 percent of South Africa's total growth over the period. Most of the expected growth relies on the accumulation of factors of production. Viewed in this context, South Africa's dynamic gains from trade associated with the TDCA look much less significant.

The paper is organized as follows. Section 2 selectively reviews the literature on trade and growth, focusing on the effect of trade openness on South African growth prospects. Section 3 outlines the sequential simulation technique used to investigate the effects of the TDCA. Section 4 reports and discusses results. Section 5 concludes. 


\section{Trade and growth in South Africa}

A standard complaint about CGE analyses of trade agreements is that most models appear to understate the long-run benefits of trade on other economic variables. Under the standard assumptions of constant returns to scale, Armington preferences and perfect competition, trade policy liberalization produces relatively small increases in output and welfare, the variables of most interest to policymakers. Furthermore, the small measured changes do not appear to be consistent with the casual observation that more open economies grow faster than closed economies. One goal of this paper is to better represent the dynamic benefits that the TDCA might bring to South Africa.

The literature on trade and growth is extensive, and we wish only to provide a sample of it here. ${ }^{1}$ It is fair to say that there is a consensus view that, ceteris paribus, economies that are open to trade will grow faster than will countries that are closed. ${ }^{2}$ Wang and Winters (1998) argue that this consensus is especially strong with respect to Africa, where decades of import substitution policies are thought to be partially responsible for the continent's dismal economic performance. Because South Africa's economy was closed during the apartheid era, dynamic gains from trade might be especially important there.

There are a number of specific channels through which more open trade might be expected to bring South Africa dynamic gains from trade. A more open trade environment might improve the quality of South Africa's capital stock if imported capital goods are of better quality, or have more variety, than

${ }^{1}$ For a comprehensive review of the literature, see U.S. International Trade Commission

2 Much of this conventional wisdom derives from cross-country growth regressions of the type employed by Sachs and Warner(1995) and Dollar(1992). Rodrik and Rodriguez (1999) have offered a cogent critique of this literature, though the consensus probably survives this assault. The estimates used in this paper are time series estimates unique to South Africa, and so are not sensitive to the Rodrik and Rodriguez critique. 
domestically produced capital goods. More open trade might stimulate more efficient domestic production by increasing competitive pressures on existing South African firms. South Africa might also benefit from new ideas and processes that accompany increased trade with a more developed partner. More open trade policies, along with access to large European markets, might also stimulate foreign direct investment, which has been linked to economic growth. While each of the channels of dynamic effects is a plausible one, it is difficult to identify the effects of any particular channel through which trade is linked to economic growth. The net effect of all these channels can, however be represented as a trade-induced increase in Total Factor Productivity (TFP).

Jonsson and Subramanian (2000) use time series data on South Africa to estimate the effect of recent changes in South African openness on growth in South African TFP. South Africa's own trade policy liberalization, combined with the end of external sanctions, provides a unique event study with sufficient variation in trade policy and openness variables to allow econometric identification of relationships between trade and growth. Jonsson and Subramanian exploit this variation to produce time series estimates of the effect of openness on growth in TFP. They estimate that a 1 percent increase in openness produces a 0.5 percent increase in manufacturing sector TFP. Because these estimates are taken from South-Africa specific data, we believe this to be among the most credible estimates of its kind. ${ }^{3}$

${ }^{3}$ There are few other natural experiments that offer such sizable variation in openness and related variables. In most cases, the relationship between trade and growth will be far less credibly estimated. 
This paper incorporates the Jonsson and Subramanian estimate into an assessment of the likely effects of the TDCA on future economic growth in South Africa. ${ }^{4}$

\section{Experiment design}

This section outlines the method used to approximate a dynamic model within the static GTAP framework. The TDCA contains a number of features that lead us to prefer a dynamic framework for the analysis of the agreement. Most importantly, the treaty is to be phased in over a 12 -year period. Because the timing of cuts varies across parties and sectors, a staged analysis that accounts for the phasing in of cuts is helpful. Moreover, since South Africa and the EU are at substantially different phases of development, sharply different factor accumulation and technical growth rates would likely lead static analysis to misrepresent the context in which various stages of the cuts are to be made.

${ }^{4}$ Our application of the Jonsson and Subramanian estimate to simulations of future openings assumes that there is no threshold effect from open trade policies. One might plausibly argue that the relationship between openness and trade is likely to be stronger in an initial opening to trade than it is in a later one. In that sense, our estimates would overstate the benefits of the TDCA on future economic growth if the marginal effect of an increase in openness on TFP is declining as openness rises. 
We prefer a framework that allows the effect of the cuts to be assessed against a dynamic baseline that represent a plausible forecast of the likely growth of the modeled economies. Using growth rates taken from World Bank forecasts, we develop an 18-year baseline that serves as the counterfactual (no policy change) against which the effects of the TDCA are measured. ${ }^{5}$

Once the baseline has been defined, implementing the shocks is a reasonably straightforward exercise. In order to provide a consistent measure of the entire impact of the treaty, we shock the model with cumulative cuts at each point in time. This asks the model what the effect of successive cuts (not just the last round of cuts) has been at a given point in time. In order to allow for lagged adjustment to tariff changes, we lag the shocks by six years. So, for example, the cumulated cuts slated to have occurred in 2006 are measured against the baseline data for $2012 .^{6}$

${ }^{5}$ As professional trade economists, we are understandably humble about the accuracy of 18-year projections of so many variables. However, as support staff for trade policymakers, we also understand that projections made by analysts are preferable in policy support decisions to a backward looking comparative static exercise. Backward-looking comparative static estimates put an unfair onus on the policymaker to interpret model results in the context of an (occasionally) uninformed projection of their own.

${ }^{6}$ The lag is somewhat long, but not incompatible with estimates of Freund and McLaren (1999), who estimate that full adjustment to EU entry takes 12 years (4 prior to the cuts and 8 after). We view the 6-year lag as consistent with a story that assumes that resource allocation is unlikely to be complete until the economy gas through a full business cycle. Because we are modeling dynamic effects that presumably lag the resource allocation effects, a lag that exceeds a common business cycle by a year or two seems appropriate. 
In order to include the dynamic benefits from trade, we must estimate the effect of each round of cuts twice. We first evaluate the effect of the cumulative cuts, allowing only allocative effects. We then calculate the model's predicted change in South Africa's openness. After applying the Johnson and Subramanian estimates to get the TDC- induced productivity (i.e., manufacturing TFP) increase, we return to the baseline data, and apply a joint shock- the policy changes and the predicted increase in manufacturing TFP. The estimates from this experiment are our preferred estimate of the effects of the TDCA.

Regional and sectoral aggregation

Because we are primarily interested in the effects of the agreement on the two partners (RSA and EU) and on the rest of Africa, our regional aggregation allows for 5 regions in the model - the European Union (EU), South Africa and the other members of the South African Customs Union, the non-SACU members of the Southern Africa Development Community (SADC), the non-SADC members in the rest of Southern Africa, and the rest of world. Commodities are aggregated into the seven sectors presented in Table 1.

Table 1. Sectoral Composition

\begin{tabular}{ll}
\hline Sectoral Aggregation & GTAP Sectors \\
\hline Agriculture & Paddy rice, Wheat, Cereal grains nec, Vegetables, fruit, nuts, Oil seeds, Sugar cane, \\
sugar beet, Plant-based fibers, Crops nec, Bovine cattle, sheep and goats, horses, & Animal products, Raw milk Wool silk-worm cocoons, Bovine cattle, sheep and goat, \\
& horse meat prods \\
Natural Resources & Forestry, Fishing, Coal, Oil, Gas, Minerals nec, Petroleum, coal products \\
Food manufacturing & Meat products nec, Vegetable oils and fats, Dairy products, Processed rice, Sugar, \\
& Food products nec, Beverages and tobacco products \\
Light manufactures & Textiles, Wearing apparel, Leather products, Wood products \\
High-tech manufactures & Metal products, Motor vehicles and parts, Transport equipment nec, Electronic \\
Heavy manufactures & equipment, Machinery and equipment nec, Manufactures nec \\
& Paper products, publishing, Chemical, rubber, plastic products, Mineral products \\
Services & nec, Ferrous metals, Metals nec \\
& Electricity, Gas manufacture, distribution, Water, Construction Trade, transport, \\
& Financial, business, recreational services, Public admin and defence, education, \\
\hline
\end{tabular}

Source: GTAP database. 


\section{Counterfactual baseline}

The next step is the creation of a reasonable baseline projection of the variables that are likely to be of interest to trade policy makers and others who wish to assess the likely impact of the Agreement. Our baseline projection is informed by outside forecasts of Gross Domestic Investment (GDI), Gross Domestic Product (GDP), and population growth that were originally made by the World Bank, and have since been incorporated into the GTAPDyn database. ${ }^{7}$ We rely on the GTAP model to determine both the manner in which the forecast growth in capital and labor are to be allocated, and the amount of technological progress (measured in growth of Hicks-neutral TFP) necessary to match the projected growth in GDP, given the World bank projections of changes in endowments of labor and capital. ${ }^{8}$ The annual growth rates that define the dynamic baseline are reported in Table $2 .{ }^{9}$

Table 2. Projected annual growth rates (1995-2018)

\begin{tabular}{l|ccc|cc}
\hline & \multicolumn{3}{c|}{ Exogenous Inputs } & \multicolumn{2}{c}{ Endogenous outputs } \\
Region & Capital & Productivity & Labor & GDP & GDP/Capita \\
\hline South Africa & 3.06 & 0.31 & 2.08 & 3.02 & 0.92 \\
SADC & 2.60 & 0.85 & 2.61 & 4.29 & 1.63 \\
Rest of Sub-Saharan Africa & 2.86 & 0.70 & 2.86 & 3.99 & 1.10 \\
EU & 1.42 & 0.92 & 0.04 & 2.57 & 2.54 \\
Rest of the world & 0.83 & 0.85 & 1.23 & 2.86 & 1.62 \\
\hline
\end{tabular}

Source: World Bank data and authors' calculations.

The figures in Table 2 describe the world, as we would expect it to be, if the TDCA were not to go into effect. In the baseline projection, factor accumulation is the engine of relatively fast growth in South Africa, while growth in capital and TFP is responsible for the slower growth in the EU. Growth

${ }^{7}$ In order to turn the projections of gross investment flows into growth in the capital stock, we assume a 2\% capital depreciation rate, so capital growth rates are calculated as the annual gross domestic investment rate less 2 percent. Furthermore, we assume that both skilled and unskilled labor change at the rate of overall population growth.

${ }^{8}$ Implied TFP growth rates are determined by adjusting model closure. GDP, by region, becomes an exogenous variable, defined by the projection, while TFP becomes an endogenous variable. Once the TFP growth rates implied by the GDP forecast have been calculated, the variables are switched once again to produce the baseline.

${ }^{9}$ The GTAPDyn database provides only a forecast from the base year (1995) through 2007. We wish to consider a longer time span. In doing so, we assume that exogenous inputs in 
rates of this level imply an estimated 71 percent growth rate in South African GDP from 2000 through 2018. In order to put the dynamic benefits of growth in context, we will evaluate the 18-year growth rate relative to this baseline.

\section{Policy shocks}

table 1 grow at the same rate from 2007 to 2018 as they are forecast to from 1995 through 2007. 
The Agreement on Trade, Development and Cooperation between the European Community and its Member States and the Republic of South Africa went into effect January 1, 2000. The agreement has several components, including agreements on development assistance, intellectual property commitments, and trade agreement. ${ }^{10}$ Here we focus on the trade provisions of the agreement. One of the main contributions of this paper is that, to our knowledge, this paper provides the first assessments of the likely impact of the TDCA using the actual cuts ratified in the treaty.

We model the implementation of the TDCA as a 3-stage liberalization, with cuts going into place at 2000, 2006, and 2012. ${ }^{11}$ Table 3 shows the phase-in period of the tariff-cuts by comparing the preference given to the other party, relative to MFN tariffs at 6-year intervals. The sectoral breakdown and the relative timing of the cuts reveal several points of interest that are relevant to our analysis. The European Union completely removes its tariffs on everything but primary products and food processing. South African concessions are not as focused on particular sectors, and are not as complete as EU cuts in manufacturing sectors. Tariffs cuts are phased in by both parties, though the EU cuts generally predate South African cuts.

${ }^{10}$ The stated objective of the TDCA (Article 1(d)) is "to promote the expansion and reciprocal liberalization of mutual trade in goods, services, and capital." Under the agreement, South Africa would open its markets to about 86 percent of EU exports over a period of 12 years, while the EU opens its markets to 95 percent of South African exports over 10 years.

${ }^{11}$ The actual phase-in is more gradual. We assume that all cuts made in the period 2001 to 2006 are implemented in 2006. 
Table 3. Negotiated preferences, percent of MFN tariffs

EU tariff cuts

\begin{tabular}{lrrr} 
Sectors & 2000 & 2006 & 2012 \\
\cline { 2 - 4 } & & & 71.02 \\
\hline Agriculture & 5.6 & 43.01 & 89.32 \\
Natural Resources & 20.08 & 27.26 & 68.87 \\
Food manufacturing & 18.66 & 29.22 & 100 \\
Light manufacturing & 21.45 & 100 & 100 \\
High-tech manufacturing & 18.3 & 99.28 & 100 \\
Heavy manufacturing & 25 & 100 & 0 \\
Services & 0 & 0 & \\
\hline
\end{tabular}

\begin{tabular}{lccr}
\hline & & & \\
& & & \\
& & & \\
Sectors & & & \\
& 2000 & 2006 & \\
\cline { 2 - 4 } & 1.39 & 33.45 & 46.07 \\
\hline Agriculture & 0 & 18.58 & 67.67 \\
Natural Resources & 2.7 & 39.53 & 88.63 \\
Food manufacturing & 0.09 & 34.39 & 61.71 \\
Light manufacturing & 0.12 & 48.42 & 92.00 \\
High-tech manufacturing & 0.01 & 45.49 & 98.42 \\
Heavy manufacturing & 0 & 0 & 0 \\
Services & & & \\
\hline Source: Authors'
\end{tabular}

Source: Authors' calculations, TDCA. 
The TDCA was negotiated under Article 24 of the GATT, which allows WTO members to enter into preferential trade agreements, provided that the agreement cover "substantially all" trade. Using historical trade as a baseline, the EU estimates that 95 percent of its total bilateral imports and 86 percent of South African imports would be covered by the TDCA. ${ }^{12}$ The standard for "substantially all" is an ambiguous one, but the rule of thumb has been that 90 percent coverage of historical trade is sufficient to satisfy the WTO. South Africa's 86 percent coverage may test the emerging 90 percent standard.

\section{Results}

In the initial liberalization, we simply include the tariff cuts in a straightforward experiment, asking the model to evaluate the allocative effects of the preferential trade liberalization between South Africa and the EU. We use the results of the allocative effects experiment to calibrate the shocks used for the dynamic effects. After calculating the change in openness from the simple experiment, we calculate the implied change in TFP from the estimated change in openness and the Jonsson and Subramanian estimate. Table 4 reports the change in openness and the implied TFP increases that are applied to produce estimates of dynamic gains from trade.

Table 4. Changes in South African openness, relative to baseline 2006-2018.

\begin{tabular}{lccr}
\hline Region & \multicolumn{3}{c}{ Percent change } \\
\hline & 2006 & 2012 & 2018 \\
\cline { 2 - 4 } Change in Openness & 0.31 & 2.42 & 3.52 \\
Associated TFP increase & 0.15 & 1.21 & 1.76 \\
\hline
\end{tabular}

Source: GTAP database and authors's calculations.

${ }^{12}$ The use of historical trade introduces a potentially important upward bias in estimates of coverage. If trade policy instruments are prohibitive, historical trade will be at or near zero. Thus, the use of historical trade as a baseline will not take into account the agreement's failure to remove prohibitive tariffs. The shortcomings of the historical approach are known to policymakers, but do not appear to have been noted in the academic literature. 
The results in Table 4 suggest that the trade policy provisions in the TDCA, when fully implemented and absorbed, are likely to increase south Africa's “openness" by 3.52 percent in the long run. ${ }^{13}$ Using the Jonsson and Subramanian estimate, this suggests that the treaty will produce a 1.76 percent increase (in levels, not growth rate) in South African TFP. We wish to explore the effects of such changes (when combined with the resource allocation changes also attributable to the treaty) on South Africa's trade and growth.

The operational procedure for such a discussion is to revert to the baseline forecast data at each period, and to shock the model with both the trade policy and the expected TFP shocks. The simultaneous shock from the baseline allows direct, coherent estimation of the impact of both the allocative and dynamic benefits of trade. The results of this exercise are reported in tables 5 to 8 . All figures are in percentage deviation from the baseline forecast.

Table 5 reports changes in the total value of bilateral trade among the regions in the model for both modeling scenarios. Table 6 reports changes in South Africa's sectoral trade flows with the EU. There is substantial evidence of both trade diversion and creation in both scenarios. When productivity gains are not accounted for, South Africa's trade with the EU rises, while trade with the remaining partners fall. The net effect appears to be trade creation, however, as South Africa's exports and imports both rise. When Productivity effects are included, South Africa imports from all non-SADC countries rise along with growth in the South African economy. The inclusion of productivity effects does not reverse the sign on its exports to any of the partners. Exports are reduced in all cases, relative to the "no productivity effects" simulation.

${ }^{13}$ Recall that the effects of the treaty are assumed to occur with a six year lag, so the final round of cuts in 2012 are not fully expressed in the model until 2018. 
Table 5. Changes in bilateral trade flows after full implementation (percent, relative to baseline)

\begin{tabular}{|c|c|c|c|c|c|c|}
\hline \multirow[b]{3}{*}{ Source } & \multicolumn{6}{|c|}{ Without productivity gains } \\
\hline & \multicolumn{6}{|c|}{ Destination } \\
\hline & $\begin{array}{l}\text { South } \\
\text { Africa }\end{array}$ & SADC & $\begin{array}{l}\text { Sub- } \\
\text { haran } \\
\text { Africa }\end{array}$ & EU & $\begin{array}{r}\text { Rest of the } \\
\text { world }\end{array}$ & Total \\
\hline South Africa & - & -3.92 & -4.88 & 15.02 & -4.72 & $\overline{1.81}$ \\
\hline SADC & -6.49 & 1.13 & 0.04 & -0.13 & 0.05 & -0.25 \\
\hline Rest of Sub-Saharan Africa & 0.59 & 0.70 & 0.15 & -0.05 & 0.02 & -0.00 \\
\hline EU & 30.05 & 0.90 & 0.06 & -0.10 & -0.08 & 0.06 \\
\hline Rest of the world & -4.81 & 0.68 & 0.13 & 0.03 & 0.02 & 0.01 \\
\hline \multirow[t]{3}{*}{ Total } & 9.11 & -0.57 & -0.07 & 0.04 & -0.03 & 0.04 \\
\hline & \multicolumn{6}{|c|}{ With productivity gains } \\
\hline & \multicolumn{5}{|c|}{ Destination } & \multirow[b]{2}{*}{ Total } \\
\hline Source & $\begin{array}{l}\text { South } \\
\text { Africa }\end{array}$ & SADC F & $\begin{array}{l}\text { Sub- } \\
\text { haran } \\
\text { Africa }\end{array}$ & EU & $\begin{array}{r}\text { Rest of the } \\
\text { world }\end{array}$ & \\
\hline South Africa & - & -5.14 & -6.72 & 10.59 & -8.61 & -1.88 \\
\hline SADC & -1.12 & 1.42 & -0.26 & -0.47 & -0.19 & -0.28 \\
\hline Rest of Sub-Saharan Africa & 4.05 & 0.98 & 0.14 & -0.07 & 0.02 & 0.01 \\
\hline EU & 26.81 & 1.48 & 0.15 & -0.08 & -0.04 & 0.08 \\
\hline Rest of the world & 0.49 & 1.04 & 0.17 & 0.01 & 0.03 & 0.03 \\
\hline Total & 10.98 & -0.62 & -0.07 & 0.02 & -0.04 & 0.03 \\
\hline
\end{tabular}

Source: GTAP database and author's calculations.

Table 6. Changes in South Africa's sectoral trade flows with the EU (percent, relative to baseline)

Exports to the EU

Agriculture

Natural Resources

Food manufacturing

Light manufacturing

High-tech manufacturing

Heavy manufacturing

Services

\begin{tabular}{rrrrrr}
\hline \multicolumn{3}{c}{ Without productivity gains } & \multicolumn{3}{c}{ With productivity gains } \\
2006 & 2012 & 2018 & 2006 & 2012 & 2018 \\
\cline { 2 - 6 } 1.42 & 20.56 & 35.17 & 0.92 & 16.49 & 27.19 \\
0.3 & -0.55 & 1.57 & -0.07 & -3.24 & -3.15 \\
27.55 & 43.44 & 159.97 & 26.74 & 36.85 & 138.6 \\
4.81 & 28.97 & 28.65 & 4.95 & 30.63 & 29.96 \\
3.81 & 18.53 & 18.2 & 3.8 & 18.72 & 17.83 \\
1.22 & 9.2 & 8.46 & 1.17 & 8.95 & 7.93 \\
-1.09 & -3.95 & -4.97 & -1.91 & -9.94 & -15.43 \\
\hline
\end{tabular}

Agriculture

Natural Resources

Food manufacturing

Light manufacturing

High-tech manufacturing

Heavy manufacturing

Services
Imports from the EU

\begin{tabular}{rrrrrr}
\hline \multicolumn{3}{c}{ Without productivity gains } & \multicolumn{3}{c}{ With productivity gains } \\
2006 & 2012 & 2018 & 2006 & 2012 & 2018 \\
\cline { 3 - 6 } & 14.06 & 23.19 & 2.29 & 16.29 & 22.44 \\
0.11 & 0.96 & 3.69 & 0.08 & 0.81 & 3.52 \\
2.79 & 32.66 & 86.99 & 3.13 & 35.96 & 80.2 \\
0.89 & 68.27 & 153.43 & 0.89 & 68.11 & 89.35 \\
0.7 & 20.76 & 48.4 & 1.01 & 23.86 & 42.84 \\
0.47 & 8.28 & 15.15 & 0.46 & 8.18 & 10.84 \\
0.58 & 2.13 & 2.72 & 1.05 & 5.9 & 9.72 \\
\hline
\end{tabular}


Table 7 reports changes in utility (equivalent variation), relative to baseline, for each of the regions in the experiment. In the standard "without productivity effects" case, both the EU and South Africa gain in welfare. When productivity effects are included, South Africa gains substantially, while the EU joins other regions of the world in suffering a net loss due to a negative terms of trade effect. 
Table 7. Changes in utility (Equivalent variation, millions of dollars, relative to baseline) Without productivity gains

\begin{tabular}{lrrr} 
& 2006 & 2012 & 2018 \\
South Africa & 100.64 & 437.85 & 574.46 \\
\cline { 2 - 4 } SADC & -8.51 & -36.71 & -54.51 \\
Rest of Sub-Saharan Africa & -3.87 & -15.79 & -21.81 \\
EU & -8.82 & 48.01 & 158.76 \\
Rest of the world & -31.58 & -298.38 & -543.29 \\
Total & 47.86 & 134.97 & 113.62 \\
\hline
\end{tabular}

\begin{tabular}{lcrr} 
& \multicolumn{3}{c}{ With productivity gains } \\
& 2006 & 2012 & 2018 \\
\cline { 2 - 4 } South Africa & 261.43 & 1703.25 & 2925.45 \\
SADC & -9.28 & -41.77 & -62.12 \\
Rest of Sub-Saharan Africa & -3.61 & -13.83 & -19.41 \\
EU & -20.94 & -30.18 & -79.4 \\
Rest of the world & -51.64 & -426.2 & -609.53 \\
Total & 175.96 & 1191.26 & 2154.99 \\
\hline
\end{tabular}

Source: GTAP database and authors's calculations.

Table 8 reports changes in GDP. In the first scenario, where productivity effect is not included, the TDCA has very small effects on output. South African output rises slightly, but most changes are virtually zero. The inclusion of dynamic gains from trade raises the impact of the treaty on South Africa substantially. South African output rises by 0.83 percent relative to the 2012 baseline, and by 1.42 percent relative to the 2018 baseline estimate. The remaining countries are not substantially effected by the output. 
Table 8. Changes in GDP (relative to baseline)

Percent

Without productivity gains

South Africa

SADC

Rest of Sub-Saharan Africa

EU

Rest of the world

\begin{tabular}{ccc}
2006 & 2012 & 2018 \\
\hline 0.01 & 0.08 & 0.06
\end{tabular}

$\begin{array}{lll}0 & -0.01 \quad-0.01\end{array}$

0

0

0

$\begin{array}{rr}-0.01 & -0.01 \\ 0 & 0\end{array}$

$0 \quad 0$

$0 \quad 0$

Value (million of dollars)

Without productivity gains

\begin{tabular}{rrr}
2006 & 2012 & 2018 \\
\hline 16.47 & 127.52 & 100.95 \\
-0.47 & -2.08 & -2.93 \\
-1.48 & -4.81 & -5.03 \\
42 & 78 & 126 \\
-8 & -64 & -104 \\
\hline
\end{tabular}

Value (million of dollars)

With productivity gains

\begin{tabular}{rrr}
2006 & 2012 & 2018 \\
\hline 153.78 & 1250.64 & 2249.09 \\
-0.52 & -2.34 & -2.86 \\
-1.42 & -4.14 & -4.55 \\
38 & 49 & 67 \\
-14 & -104 & -158
\end{tabular}

Source: GTAP database and authors's calculations.

The 1.42 percent increase in South African output that occurs as a result of the TDCA is a fairly large number for CGE studies, especially considering the fact that tariffs are only being reduced with one partner. This demonstrates the importance of dynamic gains from trade, relative to the allocative gains that are part of typical CGE experiments. When dynamic benefits are estimated credibly, as we believe they are in Jonsson and Subramanian, they are a critical to capturing all the gains from trade.

Despite the considerably larger gains, it is important to note that the staged nature of the agreement, and the assumption that the inclusion of adjustment time, spreads the growth out over a long period, approximately 18 years in this experiment. With that acknowledgment, it is useful to put trade associated GDP growth in perspective by comparing it with the projected growth over the period. Such a 
comparison can put the benefits of the TDCA in an appropriate perspective, allowing the policymaker to judge for herself whether or not the TDCA is likely to be "an engine of growth."

Figure 1 suggests that the TDCA will likely not be a major source of South Africa's economic growth in the next two decades. In fact, the three graphs are almost indistinguishable. Using the World Bank forecast as a baseline, our projections indicated that baseline growth in South African GDP would be 71 percent. Relative to the baseline growth, a 1.42 percent level effect from the TDCA appears relatively small. TDCA-induced growth accounts for only $1.42 /(71+1.42)=2$ percent of total growth over the period.

This is not to say that trade related gains are unimportant. A 1.42 percent increase in GDP from a regional FTA is a substantial gain. We view Figure 1 as an indictment of long-phase in periods for trade agreements. Almost half of the trade-related growth occurs as a result of cuts that occur in the last 6 years of the agreement. By delaying those gains out into the future, such agreements dilute the benefits of trade, when measured against other sources of growth. In assuming an adjustment period, which seems highly appropriate when estimating dynamic benefits, our model pushes the gains from trade even further back in time. If the agreement had been scheduled as a big bang in 2000, we estimate that the TDCA would have accounted for $1.42 /(19.57+1.42)=6.8$ percent of total growth over the period 2000-2006. While still relatively small, 6.8 percent of total growth is much more likely than 2 percent to be noticeable in ex post studies of the determinants of growth. 


\section{Conclusion}

In a sequential simulation study of the effects of the recent free trade agreement between the EU and South Africa, we find that the inclusion of dynamic benefits from trade substantially increases the value of the agreement to South Africa. We apply an estimate of dynamic benefits from a time series study of the post-apartheid opening of South Africa. This estimate, when combined with the negotiated tariff cuts produces a 1.42 percent increase in South African GDP, against a 0.08 percent increase when dynamic benefits are not included. This suggests that dynamic benefits can constitute a sizable portion of the gains from trade.

However, the additional GDP growth attributable to the TDCA look substantially smaller when measured against the expected growth that occurs over time. The TDCA is phased in over a twelve year period. Under the assumption that full adjustment occurs with a lag, trade induced growth appears 
relatively insignificant. We estimate that only 2 percent of total growth over the next 18 years will occur as a result of the agreement. Trade induced growth would look substantially more significant were the treaty to be implemented immediately.

\section{References}

Dollar, David "Outward-oriented Developing Economies Really Do Grow more Rapidly: Evidence from 95 LDCs, 1976-1985," Economic Development and Cultural Change, 1992, 523-544.

Edwards, Sebastian, “Openness, Productivity and Growth: What Do We Really Know?” Economic Journal 108, March 1998, 383-398.

Freund Carolyn, and John McClaren, "On the Dynamics of Trade Diversion: Evidence from Four Trade Blocs," Board of Governors of the Federal Reserve International Finance Discussion Paper \#637, June 1999.

Jonsson,Gunnar and Arvind Subramanian, "Dynamic Gains from Trade: Evidence from South Africa," IMF Working Paper, March 2000.

Rodriguez, Francisco and Dani Rodrik "Trade Policy and Economic Growth: A Skeptic's Guide to the Cross-National Evidence," mimeo, April 1999.

U.S. International Trade Commission, The Dynamic Effects of Trade Liberalization: An Empirical Analysis, USITC Publication 3069, October 1997.

Sachs Jeffery, and Andrew Warner, "Economic Reform and the Process of Global Integration," Brookings Papers on Economic Activity, 1995:1, 1-118.

Wang, Zhen Kun and L. Alan Winters, "Africa's Role in Multilateral Trade Negotiations: Past and Future," Journal of African Economies, June 1998. 